\title{
Conestat alfa for the treatment of angioedema attacks
}

This article was published in the following Dove Press journal:

Therapeutics and Clinical Risk Management

30 June 2011

Number of times this article has been viewed

\section{Benjamin Davis Jonathan A Bernstein}

University of Cincinnati College of Medicine, Department of Internal Medicine, Division of Immunology/ Allergy Section, Cincinnati, OH, USA
Correspondence: Jonathan A Bernstein 3350 Eden Avenue ML \#563, Cincinnati, $\mathrm{OH} 45267-0563$, USA

$\mathrm{Tel}+\mathrm{I}$ 5/3-558-5533

$\mathrm{Fax}+\mathrm{I}$ 5I3-558-3799

Email jonathan.bernstein@uc.edu
Abstract: Recently, multiple $\mathrm{C} 1$ inhibitor (C1-INH) replacement products have been approved for the treatment of hereditary angioedema (HAE). This review summarizes HAE and its current treatment modalities and focuses on findings from bench to bedside trials of a new C1-INH replacement, conestat alfa. Conestat alfa is unique among the other C1-INH replacement products because it is produced from transgenic rabbits rather than derived from human plasma donors, which can potentially allow an unlimited source of drug without any concern of infectious transmission. The clinical trial data generated to date indicate that conestat alfa is safe and effective for the treatment of acute HAE attacks.

Keywords: androgens, adverse events, patients, HAE attacks

\section{Hereditary angioedema Clinical presentation}

Hereditary angioedema (HAE) is a rare disorder characterized by recurrent attacks of swelling that may involve the peripheral extremities (most common), intestines, trunk, genitalia, face, and upper respiratory tract. The frequency of attacks varies greatly, but can occur as often as several times a week. Time of onset, incidence, location, and severity of clinical manifestations also vary between individuals even within the same family. ${ }^{1}$ Mechanical trauma, infections, menstruation, pregnancy, oral contraceptives, and angiotensin-converting enzyme (ACE) inhibitors are examples of potential attack triggers. ${ }^{2-4}$ Edema is not accompanied by erythema, pruritus, or urticaria and it usually resolves over a couple of days. ${ }^{5}$ Abdominal complaints are the second most frequent manifestation. Abdominal symptoms include nausea, vomiting, colicky pain, and diarrhea. ${ }^{5-7}$ These symptoms have been misinterpreted as an acute abdomen leading to unnecessary surgery. Edema of the upper airway is the most dangerous manifestation of HAE. Asphyxiation resulting in airway obstruction is the leading cause of death. ${ }^{8}$ Rarely, cerebral edema can develop with neurological symptoms. Pulmonary edema has not been reported as a common complication, presumably because bradykinin is effectively metabolized in the lung. ${ }^{9}$

\section{Epidemiology}

The prevalence of HAE has been estimated to range from 1:10,000 to 1:50,000 persons in the United States (US) ${ }^{10}$ Fifty percent of initial attacks begin in the first decade of life (average age 11 years) and an additional 30\% during the second decade of life. In undiagnosed HAE, the mortality rate can be as high as $30 \%$ to $50 \% .{ }^{11,12}$ 


\section{Mechanism}

Most HAE patients have either a quantitative (type I) or a functional (type II) defect in the $\mathrm{C} 1$ inhibitor (C1-INH), which is an important regulator of the complement, fibrinolytic, kallikrein-kinin, and coagulation pathways. ${ }^{13,14}$ For most HAE patients, inheritance is autosomal dominant, although $25 \%$ of cases can occur as the result of de novo mutations. ${ }^{15}$ However, in $5 \%$ of apparent HAE cases, no mutation of the $\mathrm{C} 1$-INH gene can be demonstrated. ${ }^{13} \mathrm{~A}$ third type of HAE, referred to as type III, characterized by normal quantitative and functional C1-INH levels and estrogen dependence, occurs more frequently in females. The original cases reported were associated with a missense mutation in Hagemann factor (Factor XII) although this observation has not been consistently observed in other cases of type III HAE. ${ }^{16}$

\section{Diagnosis}

Diagnosis may be suspected by taking a thorough history and physical examination. Typically there is a strong family history with the exception of those individuals who develop a spontaneous mutation later in life. Screening is performed by analysis of $\mathrm{C} 4$ levels, which are significantly reduced in HAE. In type I HAE, there is a quantitative decrease in serum C1-INH levels that are also functionally abnormal, whereas in type II HAE there is a normal or often elevated serum level of C1-INH but functionally reduced C1-INH activity.

Patients with type III HAE have normal quantitative and functional levels of C1-INH, but a strong family history of angioedema. This condition has been associated with a gain of function mutation in factor XII in some patients.

Genetic analysis can aid in prenatal diagnosis. However, in general, genetic studies are not required or necessary to make a diagnosis of HAE, as history, physical examination, and complement studies usually suffice. In the absence of a clear family history, up to $25 \%$ of HAE patients can have a spontaneous mutation but in these cases acquired angioedema should be excluded by obtaining a C1q complement component.

\section{Treatment}

Standard treatments for other types of angioedema, including epinephrine, corticosteroids, and $\mathrm{H} 1$ or $\mathrm{H} 2$ histamine receptor antagonists, are ineffective for HAE.${ }^{17}$ Traditional therapies for HAE, including fresh frozen plasma (FFP), $\varepsilon$-aminocaproic acid, and danazol, may be efficacious but have a negative safety profile. ${ }^{1}$ Drugs currently under investigation or recently approved to treat HAE in the US can be divided into three categories: C1-INH replacement therapies; a kallikrein inhibitor and a bradykinin receptor 2 antagonist. The C1-INH replacement therapies can be further subdivided into plasma-derived products, which include Berinert P (CSL Behring) and Cinryze ${ }^{\circledR}$ (Viropharma) and a recombinant human C1-INH, conestat alfa (Rhucin ${ }^{\circledR}$ in US, Ruconest ${ }^{\circledR}$ in Europe; Pharming). Ecallantide (Kalbitor ${ }^{\circledR}$; Dyax Corporation) is a kallikrein inhibitor and icatibant (Firzyr ${ }^{\circledR}$; Shire Pharmaceuticals) is a bradykinin receptor antagonist. Treatment of HAE includes: long-term prophylaxis with androgens (ie, danazol) or Cinryze and on-demand therapy with Berinert P, ecallantide and, when approved in the US, icatibant and conestat alfa.

\section{Acute "on-demand" treatment}

Traditionally, acute therapy for HAE in the US consisted of FFP, antifibrinolytics or high-dose androgens. As mentioned, drawbacks of using FFP include potential infection transmission and worsening of acute symptoms after administration. For $\varepsilon$-aminocaproic acid there is only anecdotal evidence of its efficacy for acute attacks. The European experience with transexamic acid is more robust but this agent is not readily available in the US for treatment of acute HAE attacks. Attenuated androgens are ineffective for acute treatment because their therapeutic effects are delayed for at least 1 to 2 days after they are started. ${ }^{1,18,36,37}$

Recently Berinert $\mathrm{P}$ and ecallantide have been approved for use of acute attack therapy in the US.

\section{Short-term prophylaxis}

Short-term prophylaxis for HAE should be initiated before any planned invasive procedure, including dental procedures if the patient has a history of swelling with trauma. Administration of FFP prophylaxis before trauma has been shown to decrease the risk of attack. ${ }^{33,34}$ Recently, a case involving a 51-year-old man with HAE who received Cinryze 1 hour before mitral valve reconstruction surgery requiring a cardiopulmonary bypass pump was reported. This case represented the first successful use of C1-INH as acute and prophylactic therapy in the US for a patient undergoing cardiac surgery requiring a cardiopulmonary bypass pump..$^{35}$

\section{Long-term prophylaxis}

In patients with more than one attack a month or with a history of life-threatening laryngeal attacks, long-term prophylaxis should be considered. ${ }^{11}$ 


\section{Specific treatments}

\section{Avoidance of triggers}

Trauma, stress, infections, ACE inhibitors, and hormone replacement therapy has been associated with angioedema attacks and should be avoided if possible in HAE patients. ${ }^{3,5,18,19}$ However, many patients with HAE have no recognizable triggers and no pre-aura that would indicate an eminent attack.

\section{Attenuated androgens}

Multiple studies demonstrate efficacy of androgens as long-term prophylaxis for HAE..$^{90-22}$ These drugs are synthetic $17-\alpha$-alkylated androgens and include danazol, stanozolol, and oxandrolone. ${ }^{6,7}$ Originally thought to be effective by increasing hepatic synthesis of C1-INH, they have been shown to be effective for type II and type III HAE as well. . $20,23,24^{2}$ Androgens have significant, common side effects including weight gain, menstrual irregularities, virilization, headache, myalgia, depression, acne, elevated liver function tests and cholesterol, and fatty liver. Other serious adverse events include myocardial infarction, stroke, acute pancreatitis, biliary hamartoma, liver cell adenoma, and hypertension. ${ }^{6,20,22,25}$

\section{Antifibrinolytics}

The antifibrinolytics, which include $\varepsilon$-aminocaproic acid and transexamic acid, are considered to be less effective for long-term prophylaxis than attenuated androgens but have been demonstrated to be effective for acute attacks. ${ }^{1,26,27}$ The mechanism of action of antifibrinolytics is not well understood. Traditionally, they were used in situations when avoidance of attenuated androgen side effects was important, particularly in children. ${ }^{28}$ Major adverse effects include thrombosis and rhabdomyolysis. ${ }^{29,30}$

\section{Fresh frozen plasma}

FFP has been used successfully for acute HAE attacks but there is increased risk of infection transmission and in some cases a paradoxical worsening of HAE has been observed.

\section{Cinryze}

The plasma-derived C1-INH replacement product, Cinryze, was approved in the US in 2008 for routine prophylaxis in adolescent and adult patients. It is produced by Viropharma, Inc. (Exton, PA) in partnership with the Sanquin Blood Supply Foundation. Sanguin produces a similar product known as $\mathrm{Cetor}^{\circledR}$, which has been on the market in the Netherlands for 11 years. Cinryze is unique in that it is pasteurized and nanofiltered C1-INH from pooled plasma of US donors. The nanofiltration step offers protection against nonenveloped viruses and prions. ${ }^{31,32}$ It is dosed twice weekly for long-term prophylaxis. To date, the only C1-INH replacement product approved for prophylactic use of HAE in the US is Cinryze.

\section{Berinert $\mathrm{P}$}

Berinert P was approved in 2009 in the US to treat acute abdominal and facial attacks in adolescents and adults and is currently approved in 28 countries worldwide. ${ }^{38}$ It is a purified human C1-INH, prepared by CSL Behring (Marburg, Germany) from the pooled plasma of US donors. There are also published reports demonstrating effectiveness of long-term prophylaxis with Berinert P. ${ }^{39}$ Berinert $\mathrm{P}$ is considered very safe to use and is administered intravenously.

\section{Ecallantide}

Ecallantide was approved in 2009 in the US to treat acute peripheral, abdominal, and laryngeal attacks in patients $\geq 16$ years old (it is currently awaiting approval in Europe).$^{40}$ It is manufactured by Dyax (Cambridge, MA). The drug inhibits plasma kallikrein, a serine protease involved in the breakdown of high-molecular-weight kininogen to bradykinin, and is an even more potent and selective inhibitor of kallikrein than $\mathrm{C} 1-\mathrm{INH} .{ }^{41}$ It is a recombinant product and therefore free of human or animal contaminants. It is administered via subcutaneous injections. ${ }^{42}$ Ecallantide is well tolerated but has been associated with a 3.9\% incidence of anaphylaxis during clinical trials. For this reason, an immunogenicity trial is to determine the ongoing risk of developing specific $\operatorname{IgG}$ and $\operatorname{IgE}$ antibodies and anaphylaxis with repeated use. ${ }^{43}$

\section{Experimental therapies for HAE}

New therapies, icatibant and conestat alfa, are under consideration for FDA approval for use in the US but have been approved for use in Europe. There continues to be a need for further investigation into both acute, short-term and longterm prophylactic treatment of HAE as well as other potential indications for these agents. For example, despite long-term prophylaxis, breakthrough angioedema attacks still occur in a significant number of patients. This has led to a dose escalating trial for Cinryze to determine the maximum safe dose required to prevent breakthrough attacks. In addition, the potential adverse effects of approved treatments (ie, anaphylaxis reports with ecallantide) have significantly limited their use. ${ }^{44}$ 


\section{Icatibant}

Clinical trials have now been completed for Icatibant in the US and it is awaiting FDA approval however, it is currently available in several European countries ${ }^{45}$ It is manufactured by the German company Jerini (Berlin, Germany). The drug is a synthetic decapeptide, similar in structure to bradykinin, which functions as a highly specific and extremely potent antagonist of the bradykinin receptor, BK2R. Icatibant is resistant to the proteolytic effects of carboxypeptidase-N and angiotensin converting enzyme, which degrade bradykinin. ${ }^{46}$ It is delivered in a subcutaneous form.

\section{Conestat alfa}

\section{Introduction to the drug}

Over the last decade the management of HAE has been dramatically changing. Biotechnical advances have allowed the emergence of numerous C1-INH replacement options that expand the ability to individualize treatment. Human C1-INH is a plasma serine protease inhibitor that inhibits proteases in the coagulation/fibrinolytic system (factor XII, factor XI, thrombin, plasmin, and tissue plasminogen activator), the complement system (C1r, C1s, MASP-1, and MASP-2), and the kinin system (kallikrein) (Figure 1). ${ }^{47}$ Plasma-derived C1-INH has been used to treat acute HAE attacks since the 1970s and has dramatically improved the outcome of laryngeal attacks in these patients in countries where it has been readily available. ${ }^{48,49}$ In 1996, the first double-blind, placebo-controlled trials documenting the efficacy of C1-INH replacement in both acute attacks and prophylaxis were reported. ${ }^{39}$ Attempts to clone C1-INH in multiple cellular expression systems has resulted in severe alterations in its

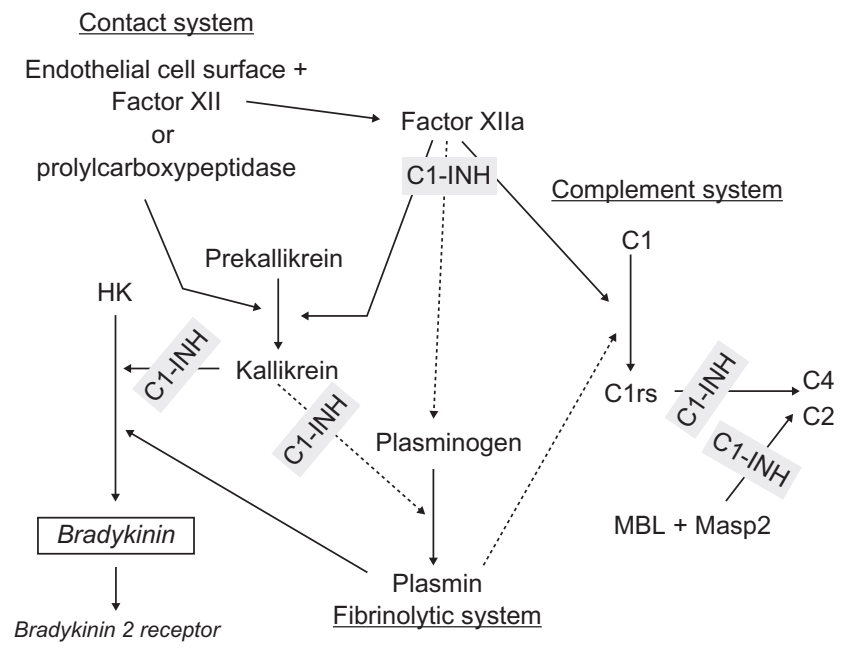

Figure I Sites of $\mathrm{Cl}$-inhibitor $(\mathrm{Cl}-\mathrm{INH})$ regulation of the contact, complement, and fibrinolytic systems. Conestat alfa, a recombinant $\mathrm{Cl}-\mathrm{INH}$, likely regulates the same sites. protein expression or conformation. ${ }^{50-53}$ In order to address the need for a readily available supply of C1-INH that was not dependent on plasma donations, the Dutch company Pharming (Leiden, the Netherlands) developed conestat alfa, a recombinant human C1-INH made from the breast milk of transgenic rabbits. Conestat alfa is being marketed under the brand name Rhucin in the US and Ruconest in Europe. The production techniques utilized to make conestat alfa have resulted in a highly purified, large quantity of functionally active product with extremely low risk of pathogen transmission. The drug has a purity level of $99.98 \%$, with $<20$ ppm of contaminants. Phase I, II, and III clinical trials have now been completed in Europe and the US. It has been approved in Europe under the name Ruconest, but approval in the US under the name Rhucin is still pending the results of a supplemental clinical trial currently in progress..$^{54}$

\section{Biochemical structure and function}

The C1-INH gene is on chromosome 11 and consists of 8 exons and 7 introns. The protein consists of 500 amino acids. ${ }^{55} \mathrm{C} 1-\mathrm{INH}$ exists in plasma as a heavily glycolated single-chain protein of 478 amino acids and weighs $105 \mathrm{kDa}$, of which approximately $50 \%$ is carbohydrate. Conestat alfa is a human plasma protease $\mathrm{C} 1-\mathrm{INH}$, recombinant protein expressed in the mammary gland of transgenic rabbits, also consisting of 478 amino acids, though it weighs less $(67,000 \mathrm{kDa})$ than human C1-INH due to less glycosylation. ${ }^{56}$ The N-glycans of conestat alfa are under-sialylated, whereas its O-glycans are over-sialylated ${ }^{57}$ Functionally, conestat alfa, compared with human C1-INH, is similar in its ability to inhibit C1, plasma kallikrein, factor XIa, and factor XIIa. Though it appears that differential glycosylation of conestat alfa relative to the human protein decreases the half-life to approximately 3 hours, this does not seem to be relevant clinically. ${ }^{2}$ Since N-linked glycosylation is important for the three-dimensional structure of protein, this process was studied in conestat alfa. It was demonstrated that the major $\mathrm{N}$-glycan structures on conestat alfa were similar to those of human C1-INH, but sialylation levels decreased with progression of lactation..$^{58}$

\section{Pharmacology}

Because C1-INH is the only known inhibitor of the classical arm of the complement pathway, in HAE, replacement of C1-INH decreases the baseline consumption of C4 in asymptomatic patients (Table 1). Hence, the pharmacodynamics of conestat alfa were analyzed by measuring $\mathrm{C} 4$ concentration and degradation in asymptomatic HAE patients. Conestat alfa exhibited dose-dependent activity both by increasing 
Table I Pharmacodynamics of C4 in asymptomatic hereditary angioedema patients

\begin{tabular}{llllll}
\hline & $\begin{array}{l}\text { Baseline serum } \\
\text { concentration }\end{array}$ & $\begin{array}{l}\text { Maximum } \\
\text { concentration } \\
\left(\mathbf{C}_{\max }, \%\right)\end{array}$ & $\begin{array}{l}\text { Time of maximum } \\
\text { concentration } \\
\left(\mathbf{T}_{\max }, \mathbf{m i n s}\right)\end{array}$ & $\begin{array}{l}\text { Minimum } \\
\text { concentration } \\
\left(\mathbf{C}_{\min }, \%\right)\end{array}$ & $\begin{array}{l}\text { Time of minimum } \\
\text { concentration }\end{array}$ \\
\hline $\mathrm{C} 4$ & $538.7(184.37)$ & $175.5(81.93)$ & $640.0(123.94)$ & $80.0(2.05)$ & $35.5(20.11)$ \\
$\mathrm{C} 4 \mathrm{~b} / \mathrm{c}$ & $107.4(58.5 \mathrm{I})$ & $5.3(1.90)$ & $40.3(39.63)$ & & \\
\hline
\end{tabular}

$\mathrm{C} 4$ levels and decreasing $\mathrm{C} 4 \mathrm{~b} / \mathrm{c}$. During HAE attacks, the C4 level peaked at 24 hours and continued to be elevated out to Day $22 .{ }^{59}$ Pharmacokinetic analysis revealed that $\mathrm{C} 1-\mathrm{INH}$ levels were elevated to twice normal levels for 2 hours and remained greater than the critical activation level of $0.4 \mathrm{U} / \mathrm{mL}$ for approximately 9 hours (Table 2 ) ${ }^{60}$ With doses ranging from $6.25 \mathrm{U} / \mathrm{kg}-100 \mathrm{U} / \mathrm{kg}$ of conestat alfa in asymptomatic patients, both maximum function of $\mathrm{C} 1-\mathrm{INH}\left(\mathrm{C}_{\max }\right)$ and the duration of C1-INH serum level above $0.4 \mathrm{U} / \mathrm{mL}$ exhibited a dosedependent increase, with ranges of $0.32 \mathrm{U} / \mathrm{mL}-2.46 \mathrm{U} / \mathrm{mL}$ and 9.1-549.7 min, respectively. During attacks in which patients were treated with $100 \mathrm{U} / \mathrm{kg}$ of conestat alfa, the $\mathrm{C}_{\text {max }}$ was $3.8 \pm 0.8 \mathrm{U} / \mathrm{mL}$ versus $2.5 \pm 0.2 \mathrm{U} / \mathrm{mL}$ in asymptomatic patients treated with the same dose. ${ }^{61}$ The dose-normalized $\mathrm{C}_{\max }$ was constant $(P=0.48)$, suggesting dose proportionality, but clearance ranged from 71.4 to $12.7 \mathrm{~mL} / \mathrm{min}$ and the elimination half-life ranged from 28 to 172 minutes depending on the dose. The pharmacokinetic data fit a 1-compartment model based on Michaelis-Menten kinetics and demonstated dose independence for maximum enzymatic activity $\left(\mathrm{V}_{\max }\right)$, which is $45 \mathrm{U} /$ minute, and the volume of distribution, which is $3.3 \mathrm{~L}$. The Michaelis-Menten constant is $0.57 \mathrm{U} / \mathrm{mL}^{62}$

Conestat alfa is freeze-dried and free of preservatives. One unit corresponds to the quantity of C1-INH present in $1 \mathrm{~mL}$ of normal fresh plasma. Conestat alfa contains 2100 units per vial after reconstitution in $14 \mathrm{~mL}$ of diluent and is administered intravenously. The maximum dose is 4200 $\mathrm{U}$ for patients with body weight $\geq 84 \mathrm{~kg}$. It is recommended that no more than two intravenous injections be administered within any 24-hour period.

\section{Safety}

No drug-related adverse events or clinically relevant vital sign changes, ECG findings, or laboratory abnormalities (including hematological, biochemical, and coagulation, viral serology, and anti-C1-INH and antibodies against rabbit milk protein) have been reported in clinical trials. The most common side effect is headache.

Blood samples from 137 HAE patients with a total of 322 treatments with conestat alfa for acute HAE attacks were tested for infectious transmission and antibodies in clinical studies. Fourteen patients had received conestat alfa for at least five acute angioedema attacks with up to 20 treatments in one patient. ${ }^{63}$ Transmission of rabbit or human viruses have not been observed. ${ }^{61,62,64}$

The frequency and amplitude of anti-conestat alfa IgG and IgM results in pretreatment versus post-treatment samples was similar, suggesting no effect of antibody generation with treatment. Positive samples did not have any detectable neutralizing antibodies. For possible antibody formation against host-related impurities (HRI), positive anti-HRI results were slightly higher for postexposure samples, but with repeated treatment there were no clinically relevant adverse events in these patients. In addition, these anti-HRI responses did not persist.

One hundred thirty-seven healthy volunteers and HAE patients were tested for the presence of $\operatorname{IgE}$ antibodies against four rabbit allergens and 10 other animal allergens after their last exposure to conestat alfa. Twenty-four out of 137 (17.5\%) subjects had at least one positive $\operatorname{IgE}$ antibody test result at baseline. Five subjects had a positive test against rabbit allergens. Three of the five subjects positive for IgE against rabbit allergens reported allergic symptoms after conestat alfa exposure. ${ }^{65}$ One healthy volunteer, who did not disclose a history of rabbit allergy and with the highest rabbit danderspecific IgE level (39 kU/L), had an anaphylactic reaction after the first exposure to conestat alfa. This has been the only severe allergic reaction to date., ${ }^{2,62,65,66}$ Three subjects

Table 2 Pharmacokinetics of conestat alpha

\begin{tabular}{llllllll}
\hline $\begin{array}{l}\text { Baseline serum } \\
\text { CI-INH } \\
\text { concentration } \\
(\mathbf{U} / \mathbf{m L})\end{array}$ & $\begin{array}{l}\text { Maximum } \\
\text { concentration } \\
\left(\mathrm{C}_{\max }, \mathrm{U} / \mathrm{mL}\right)\end{array}$ & $\begin{array}{l}\text { Dose normalized } \\
\text { maximum } \\
\text { concentration } \\
(\mathbf{U} / \mathbf{m L} / \mathrm{U} / \mathbf{k g})\end{array}$ & $\begin{array}{l}\text { Time above critical } \\
\text { concentration of } \\
\mathbf{0 . 4} \mathbf{U} / \mathbf{m L}(\mathbf{m i n})\end{array}$ & $\begin{array}{l}\text { Clearance } \\
(\mathbf{m L} / \mathbf{m i n})\end{array}$ & $\begin{array}{l}\text { Volume of } \\
\text { distribution (L) }\end{array}$ & $\begin{array}{l}\text { Half-life } \\
(\mathbf{m i n})\end{array}$ & $\begin{array}{l}\text { Maximum } \\
\text { enzymatic } \\
\text { activity } \\
\left(\mathbf{V}_{\max }\right)\end{array}$ \\
\hline $0.18(0.12)$ & $1.36(0.3 \mathrm{I})$ & $0.0236(0.00468)$ & $314.5(210.3)$ & $22.8(7.3)$ & $3.03(0.79)$ & $93.7(8.5)$ & $46.9(14.97)$ \\
\hline
\end{tabular}


had pre-existing IgE against cow milk, but none developed allergic-type symptoms on exposure to milk-derived conestat alfa. After treatment, none of the 24 subjects with pre-existing $\mathrm{IgE}$ had an increase in IgE levels to rabbit or cow milk allergens. One subject after exposure developed IgE against cow milk allergens, but not against rabbit allergens. Another subject developed IgE against rabbit meat. Neither of these two subjects developed allergic symptoms with conestat alfa exposure. ${ }^{65}$ Excluding antirabbit IgE in patients is advised before use of conestat alfa.

\section{Efficacy}

In two open-label, clinical studies on nine HAE patients who were treated with conestat alfa for 13 angioedema attacks, symptoms of attacks were assessed both by the physician and by the patients using visual analog scales (VAS, Table 3). These studies demonstrated that the median time to onset of symptom relief was $<60$ minutes, whereas median time to minimal symptoms was $<8$ hours. ${ }^{61}$ VAS scores for symptoms of peripheral attacks were obtained from 65 patients in all clinical trials. Treatment with conestat alfa significantly decreased the duration of swelling, pain and associated dysfunction of peripheral angioedema attacks in HAE patients. ${ }^{67}$

Two separate randomized, double blind, placebocontrolled clinical trials showed median time to the beginning of symptom relief and median time to minimal symptoms was significantly improved with conestat alfa. Patients were randomized to receive conestat alfa $100 \mathrm{U} / \mathrm{kg}$, $50 \mathrm{U} / \mathrm{kg}$, or placebo. For the $100 \mathrm{U} / \mathrm{kg}, 50 \mathrm{U} / \mathrm{kg}$, and placebo doses, patients reported onset of symptom relief at a median of 68 minutes, 122 minutes, and 258 minutes, respectively and time to minimal clinical symptoms of 245,247 , and 1098 minutes, respectively. These results were statistically significant relative to placebo with $P$ values $<0.01 .{ }^{64,68} \mathrm{All}$ attacks treated with conestat alfa abated, without evidence of acute recurrence or rebound, defined as an increase in the VAS to the patient's baseline score or greater after experiencing some relief within 4 hours after receiving the drug. ${ }^{64}$

To obtain further evidence about the safety and efficacy of conestat alfa, particularly with repeated dosing for recurrent attacks, open-label extensions were included as a part of the randomized studies. Sixty-five patients were treated with conestat alfa doses ranging from $2100 \mathrm{U}$ to $100 \mathrm{U} / \mathrm{kg}$. The median time to onset of relief and median time to minimal symptoms was similar to the randomized trial results. Of note, treatment was effective independent of the anatomical location. Although all doses of conestat alfa used in the openlabel extensions were effective, the $2100 \mathrm{U}$ dose appeared to be less effective. ${ }^{67,68}$

Conestat alfa appears to be safe with no reduction in effectiveness in patients receiving up to 26 treatments. Therapeutic failure, defined as time to onset of relief occurring after 4 hours, relapse within 4 hours, or the use of additional medication to treat the attack was reported in $11 \%$ and $10 \%$ of attacks treated with 50 and $100 \mathrm{U} / \mathrm{kg}$, respectively, compared with $17 \%$ for the $2100 \mathrm{U}$ dose. ${ }^{68}$ The percentage of HAE attacks responding to $50 \mathrm{U} / \mathrm{kg}$ and $100 \mathrm{U} / \mathrm{kg}$ doses of conestat alfa within 4 hours was $92 \%$ and $93 \%$, respectively, compared with $41 \%$ with placebo. Thus there appears to be no significant difference between the $50 \mathrm{U} / \mathrm{kg}$ and $100 \mathrm{U} / \mathrm{kg}$ doses. In addition, a computer simulation with a population pharmacokinetic model based on data from 214 administrations of conestat alfa in 120 patients demonstrated that doses of $50 \mathrm{U} / \mathrm{kg}$ brought functional $\mathrm{C} 1-\mathrm{INH}$ levels into normal range $(>0.7 \mathrm{U} / \mathrm{mL})$ in almost all patients and above the critical activation level $(0.4 \mathrm{U} / \mathrm{mL})$ in all patients. ${ }^{68}$ Therefore, since no further improvement was achieved with a dose of $100 \mathrm{U} / \mathrm{kg}$, the $50 \mathrm{U} / \mathrm{kg}$ dose is the recommended dose for the treatment of acute HAE attacks with conestat alfa.

Table 3 Summary of safety and efficacy trials

\begin{tabular}{|c|c|c|c|c|c|c|}
\hline & Treatment doses & Subjects & \multicolumn{3}{|l|}{ Efficacy results } & Safety results \\
\hline \multirow{3}{*}{ Phase II } & $100 \mathrm{U} / \mathrm{kg}$ within & 9 subjects with & \multirow{2}{*}{\multicolumn{3}{|c|}{$\begin{array}{l}80 \% \text { achieved symptom relief in } 2 \text { hours and minimal } \\
\text { symptoms by } 12 \text { hours }\end{array}$}} & No drug-related \\
\hline & 8 hours of attack & I 3 severe attacks & & & & adverse events or \\
\hline & & & $\begin{array}{l}\text { Time to symptom } \\
\text { relief (min) }\end{array}$ & $\begin{array}{l}\text { Time to minimal } \\
\text { symptoms ( } \mathrm{min})\end{array}$ & $\begin{array}{l}\text { Treatment } \\
\text { failure }\end{array}$ & $\begin{array}{l}\text { No postexposure } \\
\text { antibody response }\end{array}$ \\
\hline \multirow[t]{3}{*}{ Phase III } & Saline & $\mathrm{n}=29$ & 495 & 1220 & $59 \%$ & against either rhCl-INH \\
\hline & $50 \mathrm{U} / \mathrm{kg}$ & $\mathrm{n}=12$ & 122 & 247 & $0 \%$ & or rabbit-related impurities \\
\hline & $100 \mathrm{U} / \mathrm{kg}$ & $n=29$ & 66 & 266 & $10 \% *$ & \\
\hline
\end{tabular}

Note: $*$ The larger $95 \% \mathrm{Cl}$ of the odds ratios for the $50 \mathrm{U} / \mathrm{kg}$ group compared with that for the $100 \mathrm{U} / \mathrm{kg}$ group suggests no real difference in the percentage of therapeutic failures in either treatment group, which is in agreement with open label data. 


\section{Current commercial status}

Conestat alfa has been approved by the European Medicines Agency and is now available in several European countries. The FDA has delayed its approval in the US as it felt that additional therapeutic and safety analyses were necessary, which are currently ongoing.

\section{Conclusion}

In the past few years multiple C1-INH replacement products have been approved for the treatment of both acute HAE attacks and long-term prophylaxis. Conestat alfa is unique from other products as it is being produced from transgenic rabbits, which can provide a potentially unlimited source drug, which obviates the need for collecting plasma or any concerns about infectious transmission from human donors. In summary, the clinical trials to date demonstrate that conestat alfa is safe and effective for treatment of HAE attacks, independent of the anatomic location. Symptoms quickly respond ( 1 hour vs 8 hours) and resolve ( 6 hours vs 20 hours) with treatment. Unless there was a prior sensitization to rabbit allergens, no significant adverse events such as anaphylaxis have been reported. There were no laboratory abnormalities and no acute relapses or rebound attacks observed. The dose of $50 \mathrm{U} / \mathrm{kg}$ appears to be the lowest effective dose for treatment. No additional therapeutic benefit has been observed by using higher doses. Finally, no decrease in effect has been reported with repeated doses.

Conestat alfa appears to have the same biologic and clinical effect as human C1-INH. Because C1-INH concentrate is safe and effective for pediatric and pregnant patients, ${ }^{69}$ given the similar biological profile of conestat alfa to its human counterpart, it would also likely be safe and effective for these populations, but additional studies to confirm these indications have yet to be done.

In that plasma-derived $\mathrm{C} 1$-INH has been investigated as a therapy for indications other than HAE such as sepsis, acute myocardial infarction, cardiopulmonary bypass surgery, and ACE-inhibitor induced angioedema, further investigations are warranted to determine whether conestat alfa would also be effective for these indications. ${ }^{70-73}$

\section{Disclosure}

Dr Bernstein is a clinical investigator for Pharming, Dyax, Shire, ViroPharma and CSL Behring. He is a speaker for Dyax, ViroPharma and CSL Behring and a consultant for Dyax, ViroPharma, Shire and CSL Behring. Dr Davis has no disclosures to report.

\section{References}

1. Zuraw BL. Hereditary angiodema: a current state-of-the-art review, IV: short- and long-term treatment of hereditary angioedema: out with the old and in with the new? Ann Allergy. 2008;100(1 Suppl 2):S13-S18.

2. Bernstein IL. Hereditary angioedema: a current state-of-the-art review, II: historical perspective of non-histamine-induced angioedema. Ann Allergy. 2008;100(1 Supp1 2):S2-S6.

3. Nielsen EW, Gran JT, Straume B, et al. Hereditary angio-oedema: new clinical observations and autoimmune screening, complement and kallikrein-kinin analyses. J Intern Med. 1996;239(2):119-130.

4. Davis AE III. Hereditary angioedema: a current state-of-the-art review, III: mechanisms of hereditary angioedema. Ann Allergy. 2008; 100(1):S7-S12.

5. Cedzynski M, Gregorek H, Madalin'ski K. Possible dis-ease-modifying factors: the mannan-binding lectin pathway and infections in hereditary angioedema of children and adults. Arch Immunol Ther Exp Warsz. 2008;56(1):69-75.

6. Banerji A, Sloane DE, Sheffer AL. Hereditary angioedema: a current state-of-the-art review, $\mathrm{V}$ : attenuated androgens for the treatment of hereditary angioedema. Ann Allergy. 2008;100(1 Suppl 2):S19-S22.

7. Agostoni A, Cicardi M, Martignoni GC, Bergamaschini L, Marasini B Danazol and stanozolol in long-term prophylactic treatment of hereditary angioedema. J Allergy Clin Immunol. 1980;65(1):75-79.

8. Bork K, Hardt J, Schicketanz K, Ressel N. Clinical studies of sudden upper airway obstruction in patients with hereditary angioedema due to $\mathrm{C} 1$ esterase inhibitor deficiency. Arch Intern Med. 2003 . 163(10):1229-1235.

9. Gelfand JA, Sherins RJ, Alling DW, Frank MM. Treatment of hereditary angioedema with danazol. Reversal of clinical and biochemical abnormalities. N Engl J Med. 1976;295(26):1444-1448.

10. Bowen T, Cicardi M, Farkas H, et al. International consensus algorithm for the diagnosis, therapy and management of hereditary angioedema. Allergy Asthma Clin Immunol. 2010;6(1):24.

11. Cicardi M, Bergamaschini L, Marasini B, et al. Hereditary angioedema: an appraisal of 104 cases. Am J Med Sci. 1982;284(1):2-9.

12. Frank MM, Gelfand JA, Atkinson JP. Hereditary angioedema: the clinical syndrome and its management. Ann Intern Med. 1976 84(5):580-593.

13. Cicardi M, Bergamaschini L, Cugno M, et al. Pathogenetic and clinical aspects of C1 inhibitor deficiency. Immunobiology. 1998; 199(2):366-376.

14. Agostoni A, Cicardi M. Hereditary and acquired C1-inhibitor deficiency: biological and clinical characteristics in 235 patients. Medicine. 1992; 71(4):206-215.

15. Roche O, Blanch A, Caballero T, et al. Hereditary angioedema due to C1 inhibitor deficiency: patient registry and approach to the prevalence in Spain. Ann Allergy. 2005;94(4):498-503.

16. Dewald G, Bork K. Missense mutations in the coagulation factor XII (Hageman factor) gene in hereditary angioedema with normal $\mathrm{C} 1$ inhibitor. Biochem Biophys Res Commun. 2006;343(4):1286-1289.

17. Frank MM. Hereditary angioedema: the clinical syndrome and its management in the United States. Immunol Allergy Clin North Am. 2006;26(4):653-668.

18. Bowen T, Cicardi M, Bork K, et al. Hereditary angiodema: a current state-of-the-art review, VII: Canadian Hungarian 2007 International Consensus Algorithm for the Diagnosis, Therapy, and Management of Hereditary Angioedema. Ann Allergy. 2008;100(1 Suppl 2): S30-S40.

19. Agostoni A, Cicardi M, Cugno M, et al. Angioedema due to angiotensin-converting enzyme inhibitors. Immunopharmacology. 1999; 44(1-2):21-25.

20. Bork K, Bygum A, Hardt J. Benefits and risks of danazol in hereditary angioedema: a long-term survey of 118 patients. Ann Allergy. 2008; 100(2):153-161. 
21. Hosea SW, Santaella ML, Brown EJ, et al. Long-term therapy of hereditary angioedema with danazol. Ann Intern Med. 1980;93(6):809-812.

22. Cicardi M, Bergamaschini L, Cugno M, et al. Long-term treatment of hereditary angioedema with attenuated androgens: a survey of a 13-year experience. J Allergy Clin Immunol. 1991;87(4):768-773.

23. Sheffer A, Fearon D, Austen K. Clinical and biochemical effects of stanozolol therapy for hereditary angioedema. Clin Immunol. 1981;68(3):181-187.

24. Herrmann G, Schneider L, Krieg T, Hunzelmann N, ScharffetterKochanek K. Efficacy of danazol treatment in a patient with the new variant of hereditary angio-oedema (HAE III). Br J Dermatol. 2004; 150(1):157-158.

25. Cicardi M, Castelli R, Zingale LC, Agostoni A. Side effects of longterm prophylaxis with attenuated androgens in hereditary angioedema: comparison of treated and untreated patients. J Allergy Clin Immunol. 1997;99(2):194-196.

26. Frank MM, Sergent JS, Kane MA, Alling DW. Epsilon aminocaproic acid therapy of hereditary angioneurotic edema. A double-blind study. N Engl J Med. 1972;286(15):808-812.

27. Blohme G. Treatment of hereditary angioneurotic oedema with tranexamic acid: a random double-blind cross-over study. Acta Med Scand. 1972;192(4):293-298.

28. Farkas H, Varga L, Széplaki G, et al. Management of hereditary angioedema in pediatric patients. Pediatrics. 2007;120(3):e713-e722.

29. Jr J, Abrams J, Frazier O. Cooper Fatal pulmonary microthrombi during surgical therapy for end-stage heart fail-ure: possible association with antifibrinolytic therapy. Cardiovasc Surg. 2006;131(5 ):963-968.

30. Seymour BD, Rubinger M. Rhabdomyolysis induced by epsilonaminocaproic acid. Ann Pharmacother. 1997;31(1):56-58.

31. Terpstra FG, Kleijn M, Koenderman AHL, et al. Viral safety of C1-inhibitor NF. Biologicals. 2007;35(3):173-181.

32. Tateishi J, Kitamoto T, Mohri S, et al. Scrapie removal using Planova virus removal filters. Biologicals. 2001;29:17-25.

33. Atkinson JC, Frank MM. Oral manifestations and dental management of patients with hereditary angioedema. J Oral Pathol Med. 1991; 20(3):139-142.

34. Jaffe CJ, Atkinson JP, Gelfand JA, Frank MM. Hereditary angioedema: the use of fresh frozen plasma for prophylaxis in patients undergoing oral surgery. J Allergy Clin Immunol. 1975;55(6):386-393.

35. Bernstein JA, Coleman S, Bonnin AJ. Successful C1 inhibitor shortterm prophylaxis during redo mitral valve replacement in a patient with hereditary angioedema. J Cardiothorac Surg. 2010;5:86.

36. Prematta M, Gibbs JG, Pratt EL, Stoughton TR, Craig TJ. Fresh frozen plasma for the treatment of hereditary angioedema. Ann Allergy. 2007; 98(4):383-388.

37. Longhurst H. Emergency treatment of acute attacks of hereditary angiodema. Int J Clin Pract. 2005;59(5):594-599.

38. Behring C. Berinert P [package insert]. 2009:1-27.

39. Waytes AT, Rosen FS, Frank MM. Treatment of hereditary angioedema with a vapor-heated C1 inhibitor concentrate. $N$ Engl J Med. 1996; 334(25):1630-1634

40. Dyax. Kalbitor [package insert]. 2009:1-12.

41. Williams A, Baird LG. DX-88 and HAE: a developmental perspective. Transfus Apher Sci. 2003;29(3):255-258.

42. Levy JH, O'Donnell PS. The therapeutic potential of a kallikrein inhibitor for treating hereditary angioedema. Exp Opin Investig Drugs. 2006; 15(9):1077-1090.

43. Horn P, editor. Observational safety study for KALBITOR (Ecallantide) in the treatment of acute attacks of hereditary angioedema. http:// clinicaltrials.gov/ct2/show/NCT01059526?term=ecallantide\&rank $=6$. Accessed June 14, 2011.

44. Bork K, Meng G, Staubach P, Hardt J. Hereditary angioedema: new findings concerning symptoms, affected organs, and course. Am J Med. 2006;119(3):267-274.

45. European Public Access Report: Icatibant. European Medicines Agency. http://www.ema.europa.eu/docs/en_GB/document_library/ EPAR_-_Summary_for_the_public/human/000899/WC500022968. pdf. Accessed June 14, 2011.
46. Bork K, Frank J, Grundt B, et al. Treatment of acute edema attacks in hereditary angioedema with a bradykinin receptor- 2 antagonist (Icatibant). J Allergy Clin Immunol. 2007;119(6):1497-1503.

47. Davis AE, Lu F, Mejia P. C1 inhibitor, a multi-functional serine protease inhibitor. Thromb Haemost. 2010;104(5):886-893.

48. Cicardi M, Zingale L. How do we treat patients with hereditary angioedema. Transfus Apher Sci. 2003;29(3):221-227.

49. Bork K, Barnstedt SE. Treatment of 193 episodes of laryngeal edema with $\mathrm{C} 1$ inhibitor concentrate in patients with hereditary angioedema. Arch Intern Med. 2001;161(5):714-718.

50. Eldering E, Nuijens JH, Hack CE. Expression of functional human C1 inhibitor in COS cells. J Biol Chem. 1988;263(24): 11776-11779.

51. Eldering E, Huijbregts CC, Lubbers YT, Longstaff C, Hack CE. Characterization of recombinant $\mathrm{C} 1$ inhibitor $\mathrm{P} 1$ variants. J Biol Chem. 1992;267(10):7013-7020

52. Lamark $\mathrm{T}$, Ingebrigtsen $\mathrm{M}$, Bjørnstad $\mathrm{C}$, et al. Expression of active human $\mathrm{C} 1$ inhibitor serpin domain in Escherichia coli. Protein Expr Purif. 2001;22(2):349-358.

53. Wolff MW, Zhang F, Roberg JJ, et al. Expression of C1 esterase inhibitor by the baculovirus expression vector system: preparation, purification, and characterization. Protein Expr Purif. 2001;22(3):414-421.

54. Pharming. http://www.pharming.com/index.php?act=prod. Accessed June 14, 2011.

55. Carter PE, Dunbar B, Fothergill JE. Genomic and cDNA cloning of the human $\mathrm{C} 1$ inhibitor. Intron-exon junctions and comparison with other serpins. Eur J Biochem. 1988;173(1):163-169.

56. Agostoni A, Aygören-Pürsün E, Binkley KE, et al. Hereditary and acquired angioedema: problems and progress: proceedings of the third $\mathrm{C} 1$ esterase inhibitor deficiency workshop and beyond. J Allergy Clin Immunol. 2004;114(Suppl 3):S51-S131.

57. Koles K, van Berkel PHC, Pieper FR, et al. N- and O-glycans of recombinant human $\mathrm{C} 1$ inhibitor expressed in the milk of transgenic rabbits. Glycobiology. 2004;14(1):51-64.

58. Koles K, van Berkel PHC, Mannesse MLM, et al. Influence of lactation parameters on the N-glycosylation of recombinant human $\mathrm{C} 1$ inhibitor isolated from the milk of transgenic rabbits. Glycobiology. 2004; 14(11):979-986.

59. Relan A, Hack C, Haase G, Pijpstra R. Mechanistic implications from the treatment of acute angioedema attacks in Hereditary Angioedema (HAE) with recombinant human $\mathrm{C} 1$ inhibitor (rhC1INH) (poster). Complement Workshop Aug New York. 2010 SRC:1-5.

60. Späth PJ, Wüthrich B, Bütler R. Quantification of C1-inhibitor functional activities by immunodiffusion assay in plasma of patients with hereditary angioedema - evidence of a functionally critical level of C1-inhibitor concentration. Complement. 1984;1(3): $147-159$.

61. Choi G, Soeters MR, Farkas H, et al. Recombinant human C1-inhibitor in the treatment of acute angioedema attacks. Transfusion. 2007; 47(6):1028-1032.

62. van Doorn MBA, Burggraaf J, van Dam T, et al. A phase I study of recombinant human $\mathrm{C} 1$ inhibitor in asymptomatic patients with hereditary angioedema. J Allergy Clin Immunol. 2005;116(4):876-883.

63. Baboeram A, Relan A, Hack E, et al. Immunogenicity assessment of recombinant human C1 Inhibitor (rhC1INH). Allergy. 2010;65(s92): 1184

64. Zuraw B, Cicardi M, Levy RJ, et al. Recombinant human C1-inhibitor for the treatment of acute angioedema attacks in patients with hereditary angioedema. J Allergy Clin Immunol. 2010;126(4):821.e1-827.e14.

65. Pijpstra R, Hack E, Baboeram A, et al. IgE against rabbit allergens and the therapeutic use of recombinant human $\mathrm{C} 1$ inhibitor. Allergy. 2010;65:445.

66. Bernstein JA. Hereditary angioedema: a current state-of-the-art review, VIII: current status of emerging therapies. Ann Allergy. 2008;100(1):S41-S46.

67. Pijpstra R, Relan A, Haase G, et al. Clinical value of the treatment with rhC1INH of patients with hereditary angioedema suffering from an acute peripheral angioedema attack. Allergy. 2010;65:1182. 
68. Relan A, Haase G, Hack E, et al. Dose justification for recombinant human $\mathrm{C} 1 \mathrm{INH}$ for the treatment of acute angioedema attacks in patients with hereditary angioedema. Allergy. 2010;65:445-446.

69. Martinez-Saguer I, Rusicke E, Aygören-Pürsün E, et al. Characterization of acute hereditary angioedema attacks during pregnancy and breastfeeding and their treatment with $\mathrm{C} 1$ inhibitor concentrate. Am J Obstet Gynecol. 2010;203(2):131.e1-131.e7.

70. Wouters D, Wagenaar-Bos I, van Ham M. C1-inhibitor: just a serine protease inhibitor? new and old considerations on thera-peutic applications of C1-inhibitor. Expert Opin Biol Ther Aug. 2008;8(8): $1225-1240$.
71. Nuijens JH, Eerenberg-Belmer AJ, Huijbregts CC, et al. Proteolytic inactivation of plasma C1-inhibitor in sepsis. J Clin Investig. 1989; 84(2):443-450.

72. Buerke M, Murohara T, Lefer AM. Cardioprotective effects of a C1 esterase inhibitor in myocardial ischemia and reperfusion. Circulation. 1995;91(2):393-402.

73. Horstick G, Heimann A, Götze O, et al. Intracoronary application of $\mathrm{C} 1$ esterase inhibitor improves cardiac function and reduces myocardial necrosis in an experimental model of ischemia and reperfusion. Circulation. 1997;95(3):701-708.

\section{Publish your work in this journal}

Therapeutics and Clinical Risk Management is an international, peerreviewed journal of clinical therapeutics and risk management, focusing on concise rapid reporting of clinical studies in all therapeutic areas, outcomes, safety, and programs for the effective, safe, and sustained use of medicines. This journal is indexed on PubMed Central, CAS,

Submit your manuscript here: http://www.dovepress.com/therapeutics-and-clinical-risk-management-journal
EMBase, Scopus and the Elsevier Bibliographic databases. The manuscript management system is completely online and includes a very quick and fair peer-review system, which is all easy to use. Visit http://www.dovepress.com/testimonials.php to read real quotes from published authors. 